\title{
Strategic challenges in the development of teaching and learning in research-intensive universities
}

Bjørn Stensaker, Grahame Bilbow, Lori Breslow, and Rob van der Vaart

\begin{abstract}
The chapter provides an introduction to the current challenges facing many research-intensive universities throughout the world. It is argued that issues related to teaching and learning are becoming more important as a way to improve competitiveness and institutional profiling in a more globalized higher education sector. However, fostering change in research-intensive universities is often dependent on careful design addressing the normative, practical and organizational factors that may prevent institutional transformation. In the conclusion, it is underlined that initiatives that aim at cultural transformation may be a fruitful way forward for institutions trying to enhance their teaching and learning in a more systematic way.
\end{abstract}

\section{$1 \quad$ Introduction}

Higher education is one of the success stories of our time. The continuous expansion of the higher education sector in countries all over the world is a consequence of massive political, economic and cultural interest in research and education, which has led, over time, to advances in the higher education sector for individuals, nations and societies. Research universities have had a unique role in this development as they have been at the forefront of higher education institutions that have broken new ground, theoretically and empirically, and that have provided our societies with new knowledge and insights.

As a consequence, research universities have a privileged position and a long history in most economically advanced countries, and are intimately connected with the development of key functions and institutions in democratic countries. With respect to education, research universities have been the major arenas for training personnel for public bureaucracies, the legal system, health care, primary and secondary educational systems, etc. At the same time, and, as their label suggests, such institutions are still often focused on doing basic and fundamental research in a wide range of disciplines and knowledge areas. Research universities therefore reflect this interest in their internal organization, in their recruitment of academic staff, in their resource allocation, and in their decision-making.

The focus on research does not imply that research universities ignore their teaching responsibilities or their educational mission (Marincovich 2007). On the contrary, a number of pedagogical ideas and innovations in learning can be traced back to research universities, which have then spread throughout higher education. However, pedagogical and didactic 
ideas and innovations have not always been comprehensively implemented and systematically assessed within the institutions from which they originated. Reasons for this include the considerable autonomy given to individual teachers and departments, the increased number of external expectations and tasks, ingrained practices and norms about what constitutes good teaching, and a dominant focus on those activities related to research and innovation.

This situation is unfortunate in that research universities can be said to have several advantages in comparison with most other higher education institutions with respect to teaching and learning: their expertise in research and innovation provides these institutions with huge potential for finding new links between research and education, and their disciplinary scope and diversity should in principle enable these institutions to combine disciplinary insights in new ways to benefit curricula, study programmes/majors and students.

Many research universities are currently trying to develop their educational mission along these lines, and this book describes, discusses and analyzes a range of initiatives that aim to further develop the quality of teaching and learning. Although the examples reported upon and discussed in this book are taken from a relatively small sample of research universities, we believe they have considerable relevance to others by virtue of the fact that they provide cases and exemplars from leading research universities located throughout the world. Put together, they exemplify both the diversity and the commonality of approaches to strengthening teaching and learning in various institutions around the globe. Our ambition with the book is to provide both empirical evidence and critical reflections on how the quality of teaching and learning can be advanced at university level. We do not intend to offer 'best' practices in the sense that examples are unique or flawless. Our ambition is to offer 'interesting' practices so they can spur reflection and be an inspiration to other institutions in their efforts to improve teaching and learning.

\section{A broadened perspective on academic development}

Historically, academic developers and special academic development units have been central in numerous institutional efforts to improve teaching and learning (Gibbs 2013). While academic developers are still central, their roles and responsibilities, as well as their understanding of what academic development is, have changed over the years (Gosling 2009; Gibbs 2013). While academic development is a label that is closely linked to a distinct professional role for the enhancement of learning and teaching (Fraser et al. 2010), the understanding of responsibilities of academic developers varies widely from country to country, and from institution to institution (Knapper 2016). This is partly reflected in the various labels associated with academic development, also reflected in the different chapters in the current book. While in some countries the term 'educational development' is preferred, the terms 'faculty development' and 'staff development' are used in others.

Many of the activities that have taken place under these labels have been rather similar, though. Over the last couple of decades, many research universities have offered various forms of training to newly employed and established faculty focusing on how to teach, as one 
way of improving the quality of the educational enterprise. Training varies in both length and scope, but such courses have traditionally focused on the practical dimensions associated with teaching and on the individual skills of the teacher (Gibbs 2013). These kinds of courses certainly have developed substantially over the years, often recognsing the contextual, cultural or disciplinary factors that affect instruction, as well the ways in which teaching is impacted by institutional structures and regulations. Yet, it is debatable whether such individualistic approaches really have substantial, sustained, and systematic impact on the institution.

This perhaps accounts for why there has been a transformation of the role of academic development over recent years (Gibbs 2013; Knapper 2016). For example, in many European and Asian institutions, academic development has become more strongly linked to institutional strategic efforts and ambitions, is more involved in activities that are related to the structural and organisational context of teaching and learning, and is drawn into the administrative and managerial sphere of university affairs. Where this transformation has occurred, it has led to some interesting consequences for how we understand academic development. First, the blurring of boundaries between academic development and other professional activities within the university calls into question the unique responsibility of academic developers in the process of strengthening teaching and learning. The implication is that many others professionals within the university may take on distinct roles in teaching and learning improvement processes, both alongside and independently of academic developers (Fraser and Ling 2014). A second consequence is the blurring of boundaries also provides academic developers with an opportunity to expand on their tasks and responsibilities, exploring new roles and directions for how academic development could be understood in the future (Knapper 2016).

The ambition with the current book is to provide concrete examples of how a broader understanding of academic development is changing the ways research-intensive universities think about and act on improvements in teaching and learning in general. There are many approaches and tactics available for improving teaching and learning in research universities. Historically, and from a very narrow perspective, one could argue that excellent teaching and learning are dependent on the recruitment of the best academic staff and the best students. While this to some extent can be said to be true, one could also argue from a more critical perspective as to whether 'good' academic staff and 'good' students are the sole requirements for excellent teaching and learning to take place. Recent research from the US suggests that in many higher education institutions, students do not really progress academically during their college years, and questions have been raised about the added value of the education students receive (Arum and Roksa 2011). If we are to take this research seriously, it is clearly not enough to recruit brilliant staff and students. We need to understand the relationship between how faculty teach and how students learn (Trigwell et al. 1999), we need to develop a better understanding of academic practice (Brew 2010), and we need to think about how teaching and learning improvements can be linked to institutional visions and ambitions (Loads and Campbell 2015).

As research universities all over the world have grown and become more professionalized they have also expanded and built up new administrative capacity in areas 
that might influence how teaching and learning take place. Human resource management is a growing activity in most research universities, and there is an emphasis on developing research universities into leaner and more flexible organisations. Hence, the range of courses designed to develop faculty has been broadened in recent years. For example, most research universities now have courses for upcoming leaders at various levels and mentorship programmes for young staff. They also offer services to help faculty use digital tools and platforms both for instruction and for administrative functions. This kind of formalised capacity building can also - although in a more indirect way - impact how teaching is conducted and how learning takes place. One can argue that this development is actually a regulatory process that contributes to the establishment and formalisation of new rules and codes of conduct. As part of this move toward professionalisation, teaching is increasingly accompanied by stricter formal expectations and routines deriving both from the institution itself and from external constituencies (Boud and Brew 2013). As a result, in at least in some countries, there are greater demands for faculty to be certified in teaching at the university level. While this can indeed be seen as a very positive development, it is nevertheless an open question if and how these kinds of formalised approaches will work.

There is growing recognition across many institutions that the development of teaching and learning in higher education needs to depend on systematic and sustained research on the effects of curriculum, pedagogy, technology and student learning approaches (see e.g., Parpala et al. 2010). At research universities, teaching and learning-related research is increasingly an integral part of the research universities' activities. Understanding what works and what does not work with respect to teaching and learning should no longer be based on anecdotes and qualified guesses, but on systematic data collection and more rigorous research (Brew 2013).

The above stages in the development of teaching and learning are not meant as a chronological description of how this activity is unfolding (for those interested in learning more about academic development in a historical perspective, consult Gosling 2009; Gibbs 2013, Knapper 2016). While some universities perhaps have moved along rather similar development paths, others have followed quite different paths, and yet others are still pondering how to develop their strategy for improvement. Despite this diversity, most research universities have broadened their understanding of what constitutes academic development and have started to create an 'institutional tool box' to support the paths they are taking.

\section{The quest for teaching and learning improvement: a matter of engagement}

Improving teaching and learning in a systematic and comprehensive way is a considerable challenge for any university. Part of the challenge may come from the fact that research has not identified one 'best' way of organising and designing the teaching and learning enterprise. The fact that teaching and learning may be organised and structured in a variety of ways in different disciplinary settings may also complicate matters, as may the fact that universities 
are typically extremely complex organisations, characterised by competing rationales and interests.

However, in most countries there is a growing public interest in the quality of higher education. Driven by increasing accountability for how public resources are spent, by increased costs related to higher education, and by increased competition for talent, most universities are experiencing pressure to develop teaching alongside research (see, e.g. Ling et al. 2013). At research universities, this is driven less by the economic pressure of training students for employment, and more by a commitment to knowledge pursued for its own sake, and a belief that students and staff are integral to this endeavor.

An implication of this almost universal view among staff at research universities is that strengthening teaching and learning is seen less as a matter of novel digital gadgets and specific pedagogical innovations, and more as a cultural process of continuous change involving faculty and students (Knapper 2016). Within this paradigm, however, the aims and means of change need to be discussed, and advocates of particular changes need to argue for them persuasively (Brew 2010). Hence, our perspective in this book is that improvements in teaching and learning have to take account of the many cultural dimensions that are inherent in research universities, and recognize that any strategic effort must be sensitive to the historical and institutional legacies of these institutions. As such, the various chapters are very much focused on initiatives that involve and engage academic staff, who, ultimately, are the ones who will (or will not) implement new approaches to teaching and learning in their classrooms.

For those with management and leadership responsibilities, as well as for those engaged in academic development in a broad sense, this also implies that instigating change in teaching and learning is a quite challenging process that often cannot rely on traditional hierarchical decision-making and command structures. This does not mean that top-down initiatives are always flawed, or that change initiatives have to be initiated from the bottom. It rather suggests the need for coordination, consultation and sensitivity to complexity, as change processes unfold.

\section{Three grand challenges when improving teaching and learning in research universities}

Despite a broadening understanding and an increasing number of activities in the areas of academic development, pedagogical and technological change, there are still many challenges facing research universities with respect to realising their ambitions in teaching and learning, especially if they want to stimulate broader cultural shift.

On the basis of the history and key characteristics of research universities, three grand challenges can be identified as critical for such cultural change to occur. The first challenge is related to our thinking about teaching and learning, and the ways research universities have framed their role and function in the past. This can be termed the normative challenge, since 
there are certain beliefs and values that surround teaching and learning in these institutions in ways that can prevent change, although they might also point forward to future developments. The second challenge relates to how teaching and learning over time have become institutionalised in the sense that these activities manifest themselves in certain distinct practices. The practice challenge is about how to critically examine, evaluate and develop existing ways in which teaching and learning is conducted by individuals and within disciplines. Finally, and recognising that the educational mission is quite complex to administer, there is also an organisational challenge. This challenge is about how the university, in a can combine its many resources and activities more coherently so that student learning is enhanced in an optimal way.

\subsection{The normative challenge}

In most research universities, the idea of a close link between research and teaching has historically been key to steering the thinking about the role and function of education. Traditionally, the link between research and teaching stems from the Humboldtian concepts of the university, in which a key role of education was to select and train the next generation of academics. In modern research universities, the thinking around the links between teaching and learning has moved far beyond this rather limited view of the purpose of education. The modern interpretation of the coupling of research and teaching is more associated with the need for college graduates to think critically, develop analytical reasoning, and exercise independent judgment in the knowledge society. In other words, modern students should think and work as 'researchers'. According to this view, by learning how researchers approach a problem and work to solve it, students will acquire skills that are also useful both in the world of work and in other societal settings.

However, a normative challenge remains, as it is far from clear how the links between research and teaching are structured, how these activities should be structured, and how they should be rewarded. While faculty tend to believe in the value of combining research and teaching as part of their duties, the actual links between research and teaching are still relatively unexplored empirically (Hattie and Marsh 1996). One may suspect that the belief that research is only about generating knowledge and that teaching is only about disseminating knowledge prevails among university staff, although different models and perspectives do exist (Brew 2003). Hence, how we think about the relationship between research and teaching in research universities may have quite dramatic consequences for how we imagine instruction can develop critical thinking, analytical capabilities and independent judgment in students, and how the relationship between student and faculty should be structured. Some might even question whether research and teaching can be distinguished from each other (Marincovich 2007).

\subsection{The practice challenge}


Developing the quality of student learning is very dependent on critical reflections about the current practices of teaching and the impact it has on student learning. We know that teachers' approaches to teaching structure the ways in which students learn (Trigwell et al. 1999), which makes it more important than ever to critically examine the ways teaching is done and the approaches teachers use. We also know that different disciplines and subject areas have developed their own conceptions about teaching, and how it should be organised, and that distinct teaching cultures have been developed as a consequence (Umbach 2007). In the US, work has been done in what is called 'discipline-based education research' (DBER), which begins with the premise that the nature of content and skills to be mastered depends heavily on the field (Singer et al. 2012).

These cultures can be interpreted in various ways. On the one hand, they can be seen as the natural outcome of a deep understanding of specific discipline-related knowledge and how such knowledge is developing. On the other hand, they can also be seen as taken-forgranted and socially constructed practices that hinder creativity and new ways of stimulating student learning. In more complex disciplinary settings, especially when study or degree programmes are inter- or multi-disciplinary, it is still important to assess whether and in what way more generic insights into effective teaching (Chickering and Gamson 1987) can be of relevance to established practices and distinct teaching cultures in research universities.

\subsection{The organisational challenge}

Delivering education in a modern research university is a very complex activity in which a range of administrative and academic issues have to be taken into account and coordinated. Someone needs to be responsible for this coordination and for driving different activities and actions forward. If research is to be linked more strongly to teaching, there is also a question of finding the concrete ways and means to instigate such links. In short, there is an organisational challenge related to promoting and driving teaching and learning forward. One critical question to address in this respect is how 'development' is supposed to take place and what sort of structures and actions are needed to stimulate the process (Boud and Brew 2013).

It is possible to identify a range of ways forward with respect to how research universities may develop and further strengthen their teaching and learning activities. Perhaps these many possibilities lead to the diversity we see in the way academic development is designed and organized in the sector, and what seems to be a constant search for new organisational solutions (Gibbs 2013). However, the organisational challenge is not only an internal challenge. For research universities, which have well-developed external networks and partnerships with both the public and the private sector, the organisational challenge is also about how these resources can be exploited and how they can enrich the student experience. As such, the challenge is perhaps not so much about 'organisation' as it is about 'organising' - on developing adaptive structures that enable support for teaching and learning situated in complex and more networked academic environments. 


\section{The chapters in the book}

The challenges identified above are not meant to be seen as mutually exclusive. On the contrary, they are often intertwined and related to each other in very intricate ways, which is very much reflected in the different chapters in the book. The chapters expand on these challenges differently and elaborate, discuss and examine experiences that research-intensive universities in various parts of world have had when dealing with these challenges. Our intention is not to offer blueprints that we think will work in all settings. On the contrary, the cases described in the different chapters are intended to describe where problems are still found and offer critical reflections about how to move forward. We believe this is a good way to develop a better understanding of the conditions and mechanisms that need to be taken into account if teaching and learning in research universities is to be further strengthened.

As research-intensive universities in different parts of the world are trying to adapt to rapidly changing expectations and increasing demands, they face internal challenges with respect to how all new activities and actions can be coordinated. This is the topic of Chapter Two by Bjørn Stensaker, Rob van der Vaart, Tone Dyrdal Solbrekke and Line Wittek. In this chapter, they go further into what they call the expansion of academic development - how the process of developing teaching and learning is no longer the sole responsibility of academic developers. Through two case studies of the many initiatives the University of Utrecht and the University of Oslo have taken to improve teaching over the last 10-15 years, they show how these initiatives are partly a result of bottom-up initiatives, new leadership ambitions, and a more professionalised administration. These changes have led to a number of promising actions, despite some organisational fragmentation and challenges to coordination. This shift is far from unique to these two universities (Gibbs 2013), but the cases demonstrate how academic development is increasingly seen a tool for the institutional leadership to come to grips with extremely de-centralised organisation and the quite autonomous academic units within the research university.

Although modern research universities are changing - and need to do so - the goals of the change process rarely include confronting the autonomy and norms of the disciplines within the institution. Academic disciplines and disciplinary organisation lie at the heart of the research university, and successful change is often dependent on speaking to disciplinary traditions and needs (Singer et al. 2012). In Chapter Three, by Kathleen M. Quinlan, Herman Buelens, Mieke Clement, Julia Horn and Camilla Østerberg Rump, different ways and forms of engaging disciplinary specialists in teaching enhancement processes are examined through three case studies from Oxford University, the University of Leuven and the University of Copenhagen. While these universities have chosen different paths, they also share some common characteristics, including openness to discipline- specific experiences, and how this might change both the language used in development processes as well as the power relations of those involved. As such, the chapter speaks to the delicate balance that has to be found between the knowledge held by disciplinary communities (Lave and Wenger 1991), and the generic expectations concerning how teaching and learning can be improved. 
While sensitivity to the disciplinary characteristics of the research university is important, a number of research-intensive universities have, over the past decade, started to develop several institution-wide initiatives to foster improvements in teaching and learning. Among such initiatives are more formal training offered to those who take on the role as educational leader. This is a much welcome development, as educational leadership is probably one of the most challenging tasks in a research-intensive university (Bryman 2007). Through a comparison of educational leadership training programmes in several researchintensive universities, Hetty Grunefeld, Frans Prins, Jan van Tartwijk, Rob van der Vaart and colleagues describe and analyse the functioning of these programmes in Chapter Four. Through a careful examination of the different aspects of educational leadership and how it can be understood, the chapter demonstrates some common denominators of programmes, including the emphasis on interaction between participants, a practice-driven agenda and the reflective aims of the programmes.

A different institution-wide initiative which is fast becoming more popular, at least in Northern Europe, is the attempt to build the teaching competencies of academic staff through more formalised merit-based systems. Two such initiatives, from the University of Copenhagen and from the University of Edinburgh, are reported on in Chapter Five by Sofie Kobayashi, Jens Dolin, Anni Søborg and Jon Turner. While more informal training programmes for academic staff have almost become a tradition in many research-intensive universities (Umbach 2007), the initiatives described in this chapter are novel in that they see teaching competencies as a continuing process, stimulated by both the extrinsic and intrinsic motivations of the participants, and resulting in incremental and systematic cultural changes within the institutions. As the design and organisation of the two teaching competence frameworks are very different in Copenhagen and Edinburgh, the chapter also illustrates how both voluntary and more mandatory frameworks can be implemented within higher education.

Yet another initiative that is currently gaining popularity within many researchintensive universities is the establishment of so-called 'teaching academies' - entities set up with the aim of recognising, rewarding and revitalising the scholarship of teaching and learning. In Chapter Six, by Peter Geertsema, Chng Huang Hoon, Åsa Lindberg-Sand and Maria Larsson, we learn more about how teaching academies can be set up and how they can function as drivers of change within research-intensive universities (Olsson and Roxå 2013). Starting out by providing an overview of the many understandings of what a teaching academy can be, the authors provide two in-depth studies of teaching academies from the University of Singapore and the University of Lund, respectively. Although the two universities are contrasting cases concerning the ambitions of these academies, the way they have set them up, their links to other development initiatives within the universities and their effects, the analysis indicates that teaching academies can be useful and important tools for institutional and cultural change in universities.

Collegial discussions on academic questions are supposedly one of the key traits of a research-intensive university. However, as competition has tightened and as the individual performance of academic staff is more strongly rewarded, collegial discussions and collegial processes can no longer be taken for granted as a self-sustaining mechanism for critique and 
change in the research university. As underlined by Grahame Bilbow, Dai Hounsell and Tracy Zou in Chapter Seven, the essential role of such social processes should not be underestimated as a driver for change in teaching and learning. Such collegial discussions cannot just be assumed to emerge out of nothing - they must be fostered in a systematic way. At the University of Hong Kong, various ways have been found to foster systematic dialogues among academic staff and other stakeholders in teaching and learning processes. The chapter describes and analyses how these dialogues can build better mutual understanding between the different layers in the organisation and soften the tensions that can sometimes arise between academic staff and the administration. While there are many possible practices related to the enhancement of teaching and learning (Trowler et al. 2009), the Community of Practice approach taken by the University of Hong Kong, combined with 'Join-theConversation' events, will perhaps be of special interest to those who want to foster greater collegiality and dialogue around teaching and learning practices, while retaining some of the inherent and historical practices of the research-intensive university.

One of the central contributions of research universities is, of course, the new knowledge produced through systematic analysis of data and careful reflections about their implications. As such, it may be a surprise that in many research-intensive universities, the systematic gathering and utilisation of evidence of what is working with respect to teaching and learning is often missing. While much data exists, or at least has been gathered, many teaching and learning decisions in universities are made on the grounds of beliefs and assumptions rather than on solid evidence. Sari Lindblom-Ylänne and Lori Breslow demonstrate in Chapter Eight that there is much to gain from using a more evidence-based approach when trying to improve teaching and learning. By showcasing examples from the University of Helsinki and the Massachusetts Institute of Technology, they argue, in line with Kreber (2013), that by linking systematic research to initiatives designed to improve teaching, the scholarship of teaching and learning can be a collaborative learning process that may strengthen the teaching community as well as boost student learning.

\section{Academic development for cultural change}

Although the examples and cases provided in this book are diverse, both in their ambitions and in their designs, they all share some common characteristics: they tend to be collegial in their approach to change, they tend to be theoretically informed and driven by the systematic gathering and use of evidence as they have unfolded, they tend to be more contextual than local in their scope, and they attempt to be very practical and solution-oriented in their implementation. However, they all address the normative, practical and organisational challenges related to teaching and learning improvements, although in slightly different ways.

While there may be numerous beliefs and assumptions associated with what constitutes good teaching at a research-intensive university (Knapper 2016), it is unfortunate that not all of them are rooted in solid evidence of what actually works. Lindblom-Ylänne and Breslow show in their chapter that normative assumptions have a greater likelihood to be changed if they are challenged by data collected and analysed in collaboration with those who 
have hands-on responsibility for the curriculum or study programmes or majors. Such data collection and subsequent analysis also have the advantage that they lead more directly to concrete changes and adjustments, closing the gap between scholarly analysis and practice. In many ways, this is the same approach that lies behind the initiatives to build teacher competencies reported in the chapter by Dolin and colleagues. The basic idea here is that the competence of academic staff is built through teaching-oriented projects initiated and driven by participants where the systematic gathering of evidence is integral to the projects. Often this is accomplished because project leaders are asked to document the results of their efforts.

Other initiatives that address the linkages between normative challenges and the practical application of knowledge acquired are reported upon by Quinlan and colleagues. For example, 'module review assignments' ask academic staff at Oxford to review courses taught at other institutions, and they are encouraged to reflect upon how disciplinary standards are interpreted and applied by colleagues within their discipline/subject area. When KU Leuven asks disciplinary experts to identify key metaphors from within their discipline as a way to understand the essence of student learning, the point is also made that specific disciplinary practices and core ideas can inspire reflections on the normative foundations held by these experts. These 'threshold concepts' (Meyer and Land 2005) can be used to build a bridge between the disciplinary specifics and more generic ideas about effective learning.

However, the different chapters in the book also provide many examples of how practical and organisational challenges in teaching improvement processes can be addressed in integrated ways. The educational leadership programmes that are described by Grunefeld and colleagues can, for example, both be seen as very practical training opportunities for those with a special responsibility within this area, and as a way to foster on-going organisational change in educational delivery. A similar way of building organisational capacity for change is initiated through the emerging teaching academies that are discussed by Geertsema and colleagues. While these teaching academies are often initiated as reward structures for individual teachers, their ability to function as drivers of organisational change should not be underestimated. They are an example of 'alternative' ways to foster academic development through the research and the projects faculty undertake in their departments. A final example of an initiative that is intended to couple practical problems with concrete organisational solutions is the systematic dialogues that are described by Bilbow and colleagues at the University of Hong Kong. These dialogues can be said to address a recurrent problem at many universities with respect to how decisions taken to improve teaching and learning practices have tended to be rather administrative in their focus, and that 'wise' approaches for identifying change and implementing it have not been sufficiently developed. Hence, the aim of these systematic dialogues is to create communities of practice (Lave and Wenger 1991) that produce organisational impact by blurring the divide between practical challenges and organisational solutions. As such, the educational leadership programmes, the teaching academies and the systematic dialogues are all examples of building what Gibbs (2013, p.8) labels as 'change agents' in the universities concerned.

The establishment of initiatives reported upon in this book exemplifies our earlier point about the broadened view of academic development that is emerging in a number of 
research-intensive universities, and underlines the challenges of coordination and collaboration that is addressed by Stensaker and colleagues. How should activities, such as teaching academies, educational leadership training programmes and teaching competence frameworks, be coordinated and aligned? As Gosling (2009) has argued, it is often a problem finding people interested in taking on coordination roles, and attempts to centralise or decentralise responsibilities, or find suitable combinations, thus seem to be a perennial problem facing research universities. While many universities have installed processes for 'reporting' on their initiatives and projects for improving teaching and learning, it is more difficult to find examples of sustained and sustainable coordination and collaboration between the different governance levels and individual instructors who have undertaken initiatives. As we do not think that there exists a stable equilibrium with respect to the organisation of academic development in research-intensive universities, we instead opt for fostering increased cultural capital and cultural capacity to improve teaching and learning. While the current interest in enhancing teaching and learning in research-intensive universities should indeed be governed, change is still very much dependent on breaking down the boundaries between the normative, practical and organisational factors that tend to favour stability and continuation in these institutions. In this book, we hope to provide a range of examples that can inspire those on their way to break new ground in this area.

\section{References}

Arum R, Roksa J (2011) Academically adrift: Limited learning on college campuses. University of Chicago Press: Chicago.

Boud D, Brew A (2013) Reconceptualizing academic work as professional practice: Implications for academic development. International Journal of Academic Development, 18: 208-221.

Brew A (2003) Teaching and research: New relationships and their implications for inquirybased teaching and learning in higher education. Higher Education Research and Development, 22(1): 3-18.

Brew A (2010) Transforming academic practice through scholarship. International Journal for Academic Development, 15: 105-116.

Bryman A (2007) Effective leadership in higher education: A literature review. Studies in Higher Education, 32: 693-710.

Chickering AW, Gamson ZF (1987) Seven principles for good practice in undergraduate education. AAHE Bulletin, 39: 3-7.

Fraser K, Gosling D, Sorcinelli, MD (2010) Conceptualizing evolving models of education development. New directions for Teaching and Learning, 122: 49-58.

Fraser K, Ling P (2014) How academic is academic development? International Journal for Academic Development, 19: 226-241. 
Gibbs G (2013) Reflections on the changing nature of educational development. International Journal of Academic Development, 18: 4-14.

Gosling D (2009) Educational development in the UK: a complex and contradictory reality. International Journal for Academic Development, 14: 5-18.

Hattie J, Marsh HW (1996) The relationship between research and teaching: a meta-analysis. Review of Educational Research, 66: 507-542.

Knapper C (2016) does academic development matter? International Journal for Academic Development, 21: 105-115.

Kreber C (2013) Empowering the scholarship of teaching: an Arendtian and a critical perspective. Studies in Higher Education, 38: 857-869.

Lave J, Wenger E (1991) Situated learning: Legitimate peripheral participation. Cambridge, Cambridge University Press.

Ling P, Fraser K, Gosling D (2013) Welcome to 2012: Australian academic developers and student-driven university funding. International Journal for Academic Development, 18: 114126.

Loads D, Campbell F (2015) Fresh thinking about academic development: authentic, transformative, disruptive? International Journal for Academic Development, 20: 355-369.

Marincovich M (2007) Teaching and learning in a research university. In: Perry R, Smart JC (eds) The scholarship of teaching and learning in higher education: An evidence-based perspective. Dordrecht, Springer.

Meyer JH, Land R (2005) Threshold concepts and troublesome knowledge: Epistemological considerations and a conceptual framework for teaching and learning. Higher education, 49: 373-388.

Olsson T, Roxå T (2013) Assessing and rewarding excellent academic teachers for the benefit of an organization. European Journal of Higher Education, 3: 40-61.

Parpala A, Lindblom-Ylänne S, Komulainen E, Litmanen T, Hirsto L (2010) Students' approaches to learning and their experiences of the teaching-learning environment in different disciplines. British Journal of Educational Psychology, 80: 269-282.

Singer SR, Nielsen NR, Schweingruber, HA (eds) (2012) Discipline-based educational research: Understanding and improving learning in undergraduate science and engineering (Committee on the Status, Contributions, and Future Directions of Discipline-Based Education Research; Board on Science Education; Division of Behavioral and Social Sciences and Education) Washington DC, The National Academies Press.

Trigwell T, Prosser M, Waterhouse F (1999) Relations between teacher's approaches to teaching and students' approaches to learning. Higher Education, 37: 57-70. 
Trowler P, Saunders M, Bamber V (2009) Enhancement theories. In: Bamber V, Saunders M, Trowler P, Knight P (eds) Enhancing Learning, Teaching, Assessment and Curriculum in Higher Education. Maidenhead, SRHE and Open University Press.

Umbach PD (2007) Faculty cultures and college teaching. In: Perry R, Smart JC (eds) The scholarship of teaching and learning in higher education: An evidence-based perspective. Dordrecht, Springer. 